\title{
寄生真菌与百合科寄主分类学关系初探
}

赵培洁 ${ }^{1}$ 赵 怀 $^{1}$ 王慧中 $^{2}$

1 (浙江大学农业与生物技术学院，杭州 310029)

2 (杭州师范学院生物系, 杭州 310012)

摘要: 将寄生在百合科上 11 个属的真菌列成图谱, 发现霜霉目 (Peronosporales) 只寄生葱属 (Allium), 小煤矣目 (Meliolales) 只寄生菝荰属 (Smilax)。结果显示,忽属和菝苭属之间以及与其他 9 个属之间的亲缘关系均比较远, 这与哈钦松分类系统相吻合。这对有较高经济价值的百合科的分类提供了重要佐证。

关键词：百合科，植物分类，寄生性真菌

中图分类号:Q949.71+8.23 文献标识码: A 文章编号 : 1005-0094(2002)01-0024-05

\section{Taxonomy of the Liliaceae viewed from the relationship between hosts and parasitic fungi}

ZHAO Pei-Jie ${ }^{1}$, ZHAO Huai ${ }^{1}$, WANG Hui-Zhong ${ }^{2}$

1 College of Agricultural and Biological Technology , Zhejiang University , Hangzhou 310029

2 Department of Biology , Hangzhou Normal College , Hangzhou 310012

Abstract : Studying the sibship of 11 genus of Liliaceae by focusing on their parasitic fungi ,we found Peronosporales can only parasitize the Allium, while Meliola can parasitize the Smilax. The result shows that the sibships between Allium and Smilax, Allium and Samilax are distant from the other nine genus. Which coincide with the J. Hutchiuson Taxomomy system. It is important to clarify the taxonomy of Liliaceae because of its high ecomonic value. Our study provides new evidence for classification of Liliaceae.

Key words : Liliaceae ,taxonomy ,parasitic fungi

现代科学的发展正在使古老的植物分类学得到 更新和补充, 植物化学分类学 (周荣汉, 1988) 、细胞 分类学 (洪德元, 朱相云, 1987; 傅承新, 洪德元， 1990 ) 和数量分类学从多侧面提供了分类的佐证。 本文试图从另一个侧面即植物 - 真菌分类学揭示植 物系统发育的内在联系。

植物系统学的核心是建立一个植物的自然系 统”。植物的系统发育过程就是植物从其祖先演化 到现今状态的过程，这个过程既包括植物，也包括寄 生在植物上的真菌, 真菌对植物的寄生关系同样也 经历了漫长的历史进程。不同类群的真菌对寄生植 物的形态结构、化学成分、蛋白质种类要求不同。根 据寄生真菌在不同植物上的种类及其系统发育关系 推断植物的亲缘关系, 有可能为植物分类提供更可 靠的依据。基于上述考虑，我们收集、整理了国内外
百合属 (Lilium)、菝葜属 (Smilax)、葱属 (Allium)、贝 母属 ( Fritillaria)、玉篗属 (Hosta)、铃兰属 (Convallaria)、黄精属 (Polygonatum)、万年青属 (Rohdea)、 天冬属(Asparagus)、沿阶草属( Ophiopogon) 及萱草 属(Hemerocallis) 等 11 个属的病害真菌种类。本文 拟从分析比较在上述 11 个属上的专性寄生真菌、非 专性寄生真菌以及弱寄生真菌 (或腐生真菌) 类群 着手, 探讨作为寄主植物的这些属的亲缘关系 (戴 芳澜, 1979 魏景超, 1979; 浙江农业大学, 1980; 江苏 农学院,1978; 铃木直治等, 1985; 庇隆, 1987; 李尚 志,1989; 韩金声,1987; 华南农业大学,1985;王瑞 灿, 1987; 张连生等,1985;严衡元,1985; 冯天哲, 1988 ;湖南省经济作物局, 1984; 中国医学科学院药 物研究所, 1979;浙江省医药公司, 1974; 高启越, 程 新霞,1988; 李代永等,1988;王世伟等,1988;Cooke 
\& Rayner ,1984 ;Strider ,1985)。

\section{1 发生在 11 属植物上的真菌统计}

\section{1 专性寄生菌}

根据现有资料，在上述 11 个属植物上发现的专 性寄生菌分属 3 个大的类群，即卵菌(Oomycetes) 中 的霜霉目 (Peronosporales)、子囊菌 (Ascomycetes) 中 的小煤矣目 (Meliolales)、担子菌 (Basidiomycetes) 中 的锈菌目 (Uredinales)。具体如下:(1) 霜霉目: 霜 霉属 (Peronospora) ; (2) 小煤矣目:小煤矣属 (Meliola ); (3) 锈菌目:柄锈菌属 (Puccinia)、单胞锈菌属 ( Uromyces)、茁痂锈菌属 (Blastospora)、锈狍锈菌属 (Aecidium)。

11 个属的植物与以上 3 个类群的专性寄生菌 之间是否存在寄生关系表现出明显的差异, 可以粗 略地分为 3 种类型:( I ) 只能被锈菌目的专性寄生 菌寄生的植物:包括 9 个属，即百合属、贝母属、黄精 属、万年青属、玉穊属、铃兰属、天冬属、萱草属、沿阶
草属; ( II ) 能够被锈菌目和霜霉目的专性寄生菌所 寄生的植物 :如忽属; ( III) 能够被锈菌目、小煤矣目 的专性寄生菌所寄生的植物: 如菝葜属。

在类型 ( I ) 中，根据锈菌目专性寄生菌的属又 可再分为 3 种类型: ( I - - 1 ) 只能被柄锈菌属所寄生, 包括玉䙃属、铃兰属、天冬属、麦冬属、萱草属等 5 个 属; ( I - - ) 能被柄锈菌属、单狍锈菌属所寄生, 包括 百合属、贝母属 2 个属; ( I -3) 能被柄锈菌属、锈狍 锈菌属所寄生, 包括黄精属、万年青属 2 个属( 见表 $1)$ 。

\section{2 非专性寄生菌}

半知菌丛梗狍目 (Moniliales) 的叶面寄生菌, 如 葡萄狍属 (Botrytis)、尾狍属( Cercospora) 等有很强的 寄生性, 但是寄主范围比较广, 与专性寄生菌存在一 定差异。尽管如此，同一属的不同种的真菌仍表现 出一定的共性 (表 2)。

\section{3 弱寄生菌及腐生菌}

发生在 2 属植物体的弱寄生及腐生真菌见表 3 。

表 1 百合科等 11 个属上的专性寄生真菌属名

Table 1 Specialized parasitic fungi on 11 genera of family of Liliaceae

\begin{tabular}{|c|c|c|c|c|c|c|c|c|c|c|c|}
\hline \multirow[b]{2}{*}{$\begin{array}{c}\text { 专性寄生真菌属名 } \\
\text { Parasitic fungi }\end{array}$} & \multicolumn{11}{|c|}{ 寄主 Plant host } \\
\hline & $\begin{array}{l}\text { 百合属 } \\
\text { Lilium }\end{array}$ & $\begin{array}{l}\text { 菝葜属 } \\
\text { Smilax }\end{array}$ & $\begin{array}{l}\text { 葱属 } \\
\text { Allium }\end{array}$ & $\begin{array}{c}\text { 贝母属 } \\
\text { Fritillaria }\end{array}$ & $\begin{array}{c}\text { 玉䙃属 } \\
\text { Hosta }\end{array}$ & $\begin{array}{c}\text { 铃兰属 } \\
\text { Conval- } \\
\text { laria }\end{array}$ & $\begin{array}{c}\text { 黄精属 } \\
\text { Polygo- } \\
\text { natum }\end{array}$ & $\begin{array}{c}\text { 万年 } \\
\text { 青属 } \\
\text { Rohdea }\end{array}$ & $\begin{array}{c}\text { 天门冬属 } \\
\text { Aspar- } \\
\text { agus }\end{array}$ & $\begin{array}{c}\text { 麦冬属 } \\
\text { Ophio- } \\
\text { pogon }\end{array}$ & $\begin{array}{c}\text { 萱草属 } \\
\text { Hemero- } \\
\text { callis }\end{array}$ \\
\hline \multicolumn{12}{|l|}{ 霜霉目 Peronosporales } \\
\hline 霜霉属 Peronospora & & & + & & & & & & & & \\
\hline \multicolumn{12}{|l|}{ 小煤矣目 Meliolates } \\
\hline \multicolumn{12}{|l|}{ 锈菌目 Uredinales } \\
\hline 柄锈菌属 Puccinia & + & + & + & + & + & + & + & + & + & + & + \\
\hline 单胞锈菌属 Uromyces & + & & & + & & & & & & & \\
\hline 茁痂锈菌属 Blastospora & & + & & & & & & & & & \\
\hline 锈狍锈菌属 Aecidium & & + & & & & & + & + & & & \\
\hline
\end{tabular}

表 2 发生在 2 属植物以上的非专性寄生真菌

Table 2 Non-specialized parasitic fungi on more then two genera of plants

非专性寄生真菌属名

Non-specialized parasitic fungi

$$
\begin{array}{lcccc}
\text { 百合属 } & \text { 菝葜属 } & \text { 䓤属 } & \text { 贝母属 } & \text { 玉䙃属 } \\
\text { Lilium } & \text { Smilax } & \text { Allium } & \text { Fritillaria } & \text { Hosta }
\end{array}
$$

\section{寄主 Plant host}

铃兰属 黄精属 万年 天门冬属麦冬属 萱草属

Conval- Polygo- 青属 Aspar- Ophio- Hemerolaria natum Rohdea agus pogon callis

丛梗孢目 Moniliales

葡萄狍属 Botrytis elliptica

B. paeoniae 
表 3 发生在 2 属植物以上的弱寄生及腐生真菌

Table 3 Weak or saprophytic fungi on more than two genera of plants

\begin{tabular}{|c|c|c|c|c|c|c|c|c|c|c|c|c|}
\hline & \multirow[b]{2}{*}{$\begin{array}{c}\text { 真菌属名 } \\
\text { Fungi }\end{array}$} & \multicolumn{11}{|c|}{ 寄主 Plant host } \\
\hline & & $\begin{array}{l}\text { 百合属 } \\
\text { Lilium }\end{array}$ & $\begin{array}{l}\text { 菝葜属 } \\
\text { Smilax }\end{array}$ & $\begin{array}{l}\text { 䓤属 } \\
\text { Allium }\end{array}$ & $\begin{array}{c}\text { 贝母属 } \\
\text { Fritillaria }\end{array}$ & $\begin{array}{c}\text { 玉穊属 } \\
\text { Hosta }\end{array}$ & $\begin{array}{c}\text { 铃兰属 } \\
\text { Conval- } \\
\text { laria }\end{array}$ & $\begin{array}{c}\text { 黄精属 } \\
\text { Polygo- } \\
\text { natum }\end{array}$ & $\begin{array}{c}\text { 万年 } \\
\text { 青属 } \\
\text { Rohdea }\end{array}$ & $\begin{array}{c}\text { 天门冬属 } \\
\text { Aspar- } \\
\text { agus }\end{array}$ & $\begin{array}{l}\text { 麦冬属 } \\
\text { Ophio- } \\
\text { pogon }\end{array}$ & $\begin{array}{c}\text { 萱草属 } \\
\text { Hemero- } \\
\text { callis }\end{array}$ \\
\hline $\begin{array}{l}\text { 黑盘孢目 } \\
\text { Melanconiales }\end{array}$ & $\begin{array}{l}\text { 丛刺盘矜属 } \\
\text { Vermicularia }\end{array}$ & + & & & + & & + & & & & + & + \\
\hline $\begin{array}{l}\text { 多孢菌目 } \\
\text { Polyporales }\end{array}$ & $\begin{array}{l}\text { 网膜革菌属 } \\
\text { Pellicularia }\end{array}$ & + & & + & & + & + & & & & & + \\
\hline $\begin{array}{l}\text { 座囊菌目 } \\
\text { Dothideales }\end{array}$ & $\begin{array}{l}\text { 多孢小球壳属 } \\
\text { Sphaerulina }\end{array}$ & & & & & & & & + & & + & \\
\hline $\begin{array}{l}\text { 丛梗狍目 } \\
\text { Moniliales }\end{array}$ & $\begin{array}{l}\text { 镰刀菌属 } \\
\text { Fusarium }\end{array}$ & & & & + & & & + & & & & \\
\hline $\begin{array}{l}\text { 无匏菌目 } \\
\text { Mycelia }\end{array}$ & $\begin{array}{l}\text { 小菌核菌属 } \\
\text { Sclerotium }\end{array}$ & + & & & & & + & & & & & \\
\hline
\end{tabular}

2 寄主植物间亲缘关系在寄生菌类群方面 的反映

根据表 1 可绘制出图 1。如图 1 所示, 上述 11 个属分为 3 类,其中第 I 类的 9 个属中百合属和贝 母属、黄精属和万年青属亲缘关系最近; 第 III 类 ( 菝 荰属) 和第 I 类的关系相对比较密切, 具体表现为 菝荰属还能被锈狍锈菌属 (Aecidium) 所寄生; ; 同 I3 类) 而第 II 类 (忽属) 与第 I 类的亲缘关系则明显 地远得多。

根据 11 个属上的专性寄生真菌类群虽然已经 粗略勾勒出它们之间亲缘关系的总体概貌，但是仍 有不少细节不清楚，如 I -1 类型中的 5 个属。图 1 所示的亲缘关系图也需要进一步的参考佐证。

综合表 1 、表 2 和表 3 将这 11 个属的亲缘关系 可进一步表述如图 2。如表 2 所示,玉穊属和铃兰 属以及黄精属可以被同一个种的葡萄狍属真菌所寄 生, 这一方面反映了玉雗属与铃兰属之间密切的亲 缘关系,也反映了这 2 个属与黄精属具较近的亲缘 关系。天门冬、麦冬 2 属可以被交链狍属真菌所寄 生 (同贝母、玉䙃 2 属)，同样也反映了天门冬、麦冬 2 属具有密切的亲缘关系, 但是它们在与玉籫、贝母 2 属的亲缘关系上并不是等距的。因为贝母属属于 I -2 类型,而玉䙃和天门冬及麦冬这 2 个属却同属 I -1 类型, 因此, 天冬属和麦冬属与玉雗属的亲缘 关系相对要近些。萱草尾狍菌可以侵染萱草属、玉 籫属的事实，也揭示了这 2 个属具较近的亲缘关系。 这样，I -1 类型中 5 个属在这 11 个属中的亲缘关系 就明确了。
需要说明的是, 葡萄狍属 (Botrytis) 和交链狍属 (Alternaria) 虽然都是非专性寄生菌, 但在寄生性方 面前者强于后者, 这一点在确定有关亲缘关系细节 时我们也给予了一定的考虑。

表 3 所列的弱寄生菌及腐生菌有两种情况:种是寄主范围相对较窄、寄生性相对较强一些，如黑 盘狍目丛刺盘狍属的百合炭疽菌 (Colletotrichum liliaceae)、座囊菌目多狍小球壳属的万年青多狍小球 壳菌 (Sphaerulina rohdeae)。通过它们在 11 个属上 的发生情况, 可以用来验证和补充对其亲缘关系的 推断; 另一种则主要是营腐生生活, 寄主范围常涉及 到单子叶和双子叶植物的不少目和科, 参考价值也 小得多,如表 3 中的网膜革菌属 (Pellicularia) 和镰 刀菌属 (Fusarium)。

\section{3 结论与讨论}

将图 2 所示的百合科 11 个属的亲缘关系与经 典植物分类学,包括形态、数量、化学和细胞分类学 的研究结果作一比较 (汤彦承,梁松筠, 1983 汪劲 武, 1985; 侯宽绍, 1982; 中国科学院植物研究所, 1987 ;丁景和,曾万章, 1985; 中山大学生物系,南京 大学生物系, 1978; 周荣汉, 1988; 华东师范大学等, 1983 ;洪德元,朱相云, 1987; 傅承新,洪德元,1990； 胡先骕，1958），可喜的是前者与后者基本一致。因 此, 可以认为寄生真菌在植物分类学上有重要的佐 证作用, 这也从一个侧面反映了缤纷繁复的生物之 间的内在联系。

本文所提及的真菌都是对植物有致病作用的病 


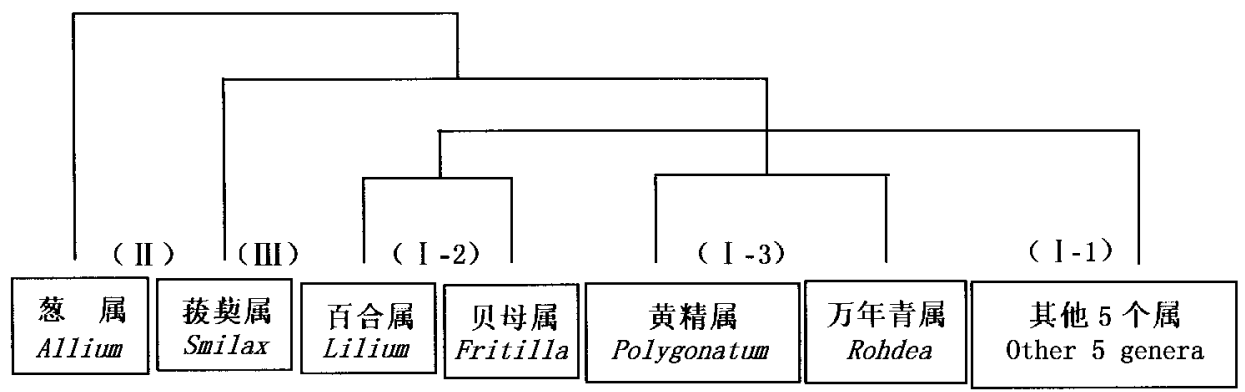

图 1 百合科 11 个属的亲缘关系

Fig. 1 The 11 Sibships of Liliaceae

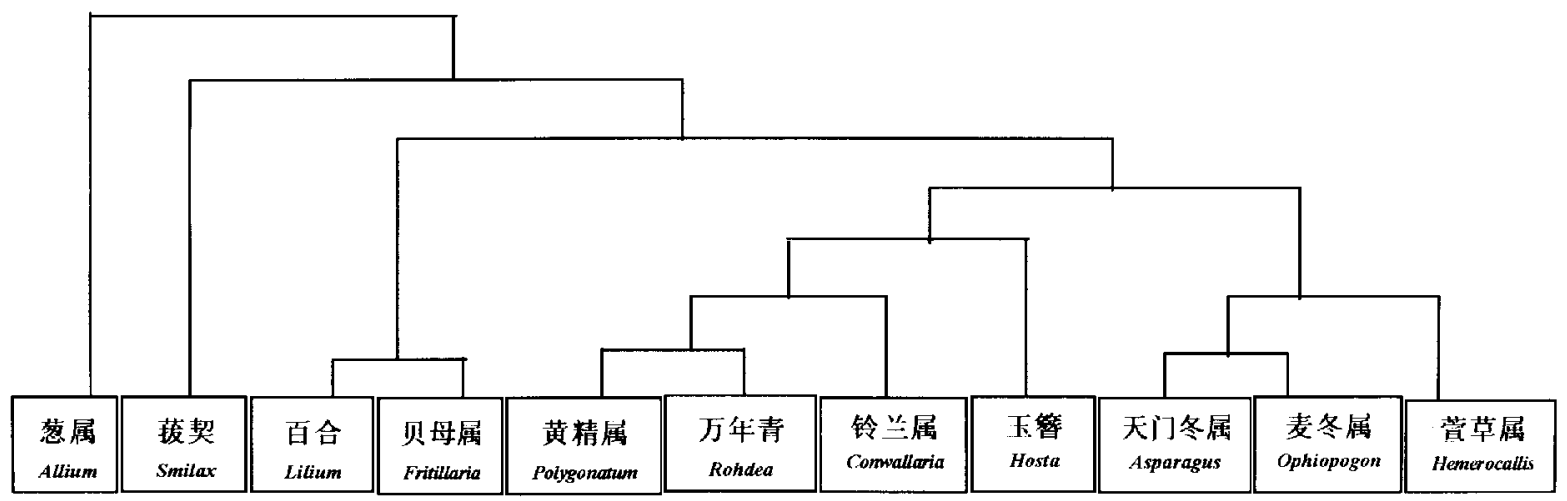

图 2 百合科 11 个属的亲缘关系

Fig. 2 The 11 Sibships of Liliaceae

原真菌。植物的茎叶表面具有蜡质或角质的保护 层, 病原菌侵入表皮必须具有相应的分解酶。植物 细胞有纤维素和果胶质构成的细胞壁, 由于构成细 胞壁成分的多糖类的分子结构是多样的, 病原菌产 生的酶也必须具有相应的特异性, 这就为病原真菌 寄主范围的解释提供了依据。从植物系统发育的原 理来说, 亲缘关系越近, 其茎叶表面的保护层及细胞 壁的成分也越接近，从而更容易被同属或同种病原 菌所侵染。

寄主植物和病原真菌之间的寄生关系是经过了 漫长的时间才建立起来的,也经历了长期的演化过 程。考察这种寄生关系与考察植物的形态结构、化 学成分、基因图谱一样, 可以为建立一个更符合事实 的分类系统提供重要的参考佐证。

病原真菌与寄主植物之间的寄生关系有专性寄 生、非专性寄生、弱寄生 (或腐生) 3 种类型。专性寄 生真菌只能在寄主活体内存活，实质上是一种共生 关系, 这种关系的建立比非专性寄生、弱寄生要求更 严格，经历的演化过程也必然更长，由此可以推测能 够被同属或同种专性真菌所寄生的寄主植物其进化
渊源也更接近。

笔者认为专性寄生关系是考察寄主植物亲缘关 系的最重要的尺度之一, 非专性寄生关系次之, 弱寄 生关系更次之。

\section{参考文献}

戴芳澜, 1979. 中国真菌总汇. 北京: 科学出版社

丁景和, 曾万章, 1985. 药用植物学. 上海: 上海科技出版社,

$$
225 \sim 231
$$

冯天哲, 1988. 常见花卉主要病虫害防治技术. 北京: 农业出 版社

傅承新, 洪德元, 1990. 浙江产 7 种菝荔的染色体研究. 植物 分类学报, $\mathbf{2 8}(3): 211 \sim 222$

高启越, 程新霞, 1988. 药用植物病害防治. 合肥: 安徽科技 出版社, $36 \sim 37,41 \sim 42,58 \sim 60$

韩金声, 1987. 花卉病害防治. 昆明: 云南科技出版社

洪德元, 朱相云, 1987. 百合科细胞分类学研究 (1). 植物分 类学报, $25(4): 245 \sim 253$

侯宽绍, 1982. 中国种子植物科属辞典. 北京: 科学出版社, $583 \sim 584$

湖南省经济作物局 (编), 1984. 怎样栽培黄花菜. 上海: 上海 科技出版社, $77 \sim 90$

胡先骕, 1958. 植物分类学简编. 北京: 科学技术出版社, $288 \sim 299,428$ 
华东师范大学, 东北师范大学, 1983. 植物学. 北京: 人民教 育出版社

华南农业大学, 1985. 花木病虫害防治. 广州: 广东科技出版 社

江苏农学院, 1978. 植物病害诊断. 北京: 农业出版社, 245 $\sim 246,262$

李代永, 陶长银, 陈仕昌, 1988. 湖贝鳞茎腐烂病的防治研 究. 中药通报, 13(9): 13 15

李尚志, 1989. 花卉病害与防治. 北京: 中国林业出版社

铃木直治, 大内成志, 道家纪志 (著) (昭和 53 年), 张际中, 刘 显章, 张泳峰, 王崇仁 (译), 1985. 近代植物病理化学. 上海: 上海科技出版社, $49 \sim 62$

庇隆(著), 1978. 沈瑞祥, 段道怀, 周仲铭( 译), 1987 , 花木病 虫害. 北京: 建筑工业出版社, 124, 178, 233, 267, 300, 426

汤彦承, 梁松筠, 1983. 中国百合科的系统梗概及对今后研 究的一些意见. 植物研究, 3(2): 56 72

汪劲武, 1985. 种子植物分类学. 北京: 高等教育出版社, $231 \sim 237,273 \sim 308$

王瑞灿, 1987. 观赏花卉病虫害. 上海: 上海科技出版社

王世伟, 刘桂华, 易飞, 1988. 云南主要药用植物病虫害考
察. 中药通报, 13(3):20 25

魏景超, 1979. 真菌鉴定手册. 上海: 上海科技出版社

严衡元, 1985. 花卉病虫害防治. 杭州: 浙江科技出版社

张连生, 张良玉, 傅新生, 1985. 花卉病虫害及其防治. 天津: 天津科学出版社

浙江农业大学, 1980. 农业植物病理学(下册). 上海: 上海科 技出版社, $365 \sim 370,283 \sim 291$

浙江省医药公司, 1974. 药材病虫害防治. 北京: 人民卫生出 版社, $72 \sim 77$

中国科学院植物研究所 (主编), 1976. 中国高等植物图鉴 (第五册). 北京: 科学出版社, 913 919

中国医学科学院药物研究所, 1979. 药用植物栽培技术. 北 京: 农业出版社, 184 192

中山大学生物系, 南京大学生物系, 1978. 植物学(系统分类 部分). 北京: 人民教育出版社

周荣汉, 1988. 药用植物化学分类学. 上海: 上海科学技术出 版社, $330 \sim 338$

Cooke R and C Rayner, 1984. Ecology of Saprotrophic Furgi. Longman, New York, 124:228 317

Strider D L, 1985. Botrytis gray mold. Diseases of Floral Crops, 2: $200 \sim 205$

(责任编辑：孙大川、时意专)

\section{生物多样性研究丛书}

1 生物多样性研究丛书

(1)《生物多样性研究的原理与方法》(中国科学院生物 多样性委员会) 27.50 元/本

(2)《保护生物学》(蒋志刚/马克平主编) 35.00 元/本

(3)《物种多样性研究与保护》(宋延龄、杨亲二等主编) 38.50 元/本

(4)《中国动植物遗传多样性》(胡志昂/张亚平主编) 35.00 元 $/$ 本

(5)《遗传多样性研究的原理与方法》(季维智、宿兵主 编) 38.80 元 $/$ 本

(6)《系统与进化植物学中的分子标记》(邹喻苹、葛颂等 编著) 35.00 元 $/$ 本

(7)《中国重点地区与类型生态系统多样性》( 马克平主 编) 43.80 元 $/$ 本

(8)《中国森林多样性及其地理分布》(陈灵芝主编) 35.00 元 $/$ 本
(9)《人类活动对生态系统多样性的影响》(陈灵 芝、王祖望主编) 42.00 元/本

(10)《生物多样性与人类未来一一第二届全国生物 多样性保护与持续利用研讨会论文集》 80 . 00 元 $/$ 本

(11)《面向 21 世纪的中国生物多样性保护》一一第 三届全国生物多样性保护与持续利用研讨会论 文集》 80.00 元/本

(12)《生物多样性科学: 原理与实践》(陈灵芝、马克 平主编) 44.00 元/本

2 生物多样性译丛

(1)《生物多样性译丛 (三)》 41.00 元/本

(2)《生物多样性公约指南》 ( 又名《生物多样性译 丛 (四)》) 30.00 元/本

邮购请汇款到编辑部, 并请另加书款 $10 \%$ 的邮挂费。

本刊e-mail 地址 biodiv@caf. forestry. ac.cn 